\title{
INTERACTIONS BETWEEN GLYPHOSATE, FUSARIUM INFECTION OF WATERHEMP, AND SOIL MICROORGANISMS
}

\author{
Kristin K. Rosenbaum \\ Dr. Kevin W. Bradley, Dissertation Supervisor \\ SHORT ACADEMIC ABSTRACT
}

In recent years, an increasing number of weed populations have been characterized with resistance to the herbicide glyphosate. In particular, waterhemp has evolved glyphosate resistance (GR) across numerous soybean fields in Missouri. Therefore research is needed to determine best management practices for GR weed biotypes. The objectives of these experiments were to determine the frequency and distribution of GR waterhemp in Missouri and identify any in-field parameters which could serve as indicators of GR in future crop production systems; determine the effects of various pre-emergence (PRE) and post-emergence (POST) herbicide programs on palmer amaranth and waterhemp control, soybean yield, and net income in conventional, glyphosate-resistant, and glufosinate-resistant soybean production systems; determine the effects of soil microbial and phytopathogen populations on GR and susceptible (GS) waterhemp survival and Fusarium infection; and determine the soil microbial abundance and diversity in soils collected from soybean fields with differences in waterhemp biotypes and herbicide and crop rotation histories. Results from these experiments indicate herbicide programs that contain PRE herbicide treatments provide the best opportunity for season-long control of waterhemp and palmer amaranth, highest grain yields, and highest net returns in the soybean systems evaluated. GR was confirmed in $69 \%$ of the total waterhemp populations sampled in Missouri. Additionally, the in-field parameters evaluated suggest that soybean fields containing GR waterhemp were more likely to be free of other weed species, occur where soybeans were continuously cropped, occur where glyphosate was the only herbicide applied for several seasons consecutively, and where waterhemp exhibited signs of surviving herbicide treatment compared to fields characterized with GS waterhemp. Results of the soil study indicate plants are more sensitive to glyphosate in soils with microbial populations compared to those without and that glyphosate may predispose plants to soilborne phytopathogens. The results also suggest continuous use of glyphosate does not significantly affect soil microbial abundance or diversity. 